\title{
A ESCUTA NA PRÁTICA PEDAGÓGICA: algumas considerações
}

\author{
LISTENING IN PEDAGOGICAL PRACTICE: some considerations
}

LA ESCUCHA EN LA PRÁCTICA PEDAGÓGICA: algunas consideraciones

\author{
Maria Verónica Pascucci \\ Professora Mestre do Departamento de Música da Universidade Federal do Maranhão. \\ São Luís, MA - Brasil. \\ veronicapascucci@hotmail.com
}

RESUMO: O presente trabalho parte de uma observação reflexiva da obra de Barlach intitulada Der Fries der Lauschenden e traça possíveis nexos entre a forma de escuta sugerida e a escuta necessária à prática pedagógica que implica um ouvir a si mesmo para poder ouvir o outro. Desde o ponto de vista filosófico essa escuta é a capacidade de ouvir a voz que orienta a vida e na prática pedagógica, uma disposição de abertura aos sentidos e significados de si, do outro e do mundo.

PALAVRAS-CHAVE: Escuta. Atenção. Cuidado.

ABSTRACT: This paper begins in a reflective observation of the work of Barlach entitled Der Fries der Lauschenden and delineates possible links between the suggested listening, and the necessary listening for educational practice that involves listening to oneself in order to listen to others. From the philosophical point of view, this listening is the ability to hear the voice that guides life and pedagogical practice, an opening to the senses and meanings of oneself, of others and of the world.

KEYWORDS: Listening. Attention. Care.

RESUMEN: El presente trabajo parte de una observación reflexiva de la obra de Barlach denominda Der Fries der Lauschenden, y establece posibles conexiones entre la forma de escucha sugerida y la escucha necesaria a la práctica pedagógica que implica un oír a sí mismo para poder oír el otro. Desde el punto de vista filosófico esta escucha es la capacidad de oír la voz que orienta la vida y en la práctica pedagógica, una disposición de abertura a los sentidos y significados de sí, del otro y del mundo.

Palabras clave: Escucha. Atención. Cuidado.

PALABRAS CLAVE: Escucha. Atención. Cuidado. 


\section{1| INTRODUÇÃO}

As considerações apresentadas neste artigo surgiram a partir da observação da obra de Barlach intitulada Der Fries der Lauschenden, traduzida como O friso dos espreitantes ou O friso da escuta, ou Friso dos que estão à espreita/escuta. Porém, antes de mergulharmos nas imagens e no que elas suscitam, queremos destacar algumas informações importantes sobre o autor e sua obra. Barlach nasceu em Wedel, Alemanha, em 1870 e faleceu em Rostock, em 1938. Representante do expressionismo alemão, foi escultor e escritor, sua obra está marcada por um profundo misticismo. Trabalhou em madeira, terracota, porcelana e bronze. Tanto na escultura quanto nas letras, não faz distinção entre sonho e verdade, vida real ou imaginária. Sua obra revela tristeza e solidão. Nos últimos anos da sua vida sofre a opressão do nazismo que retirou e destruiu algumas de suas obras, por considera-las "arte degenerada". Somente após o término da segunda guerra, sua arte e sua obra foram reconhecidas.

No que diz respeito ao Fries der Lauschenden, Barlach esculpiu inicialmente, em 1926, sete figuras destinadas a fazer parte de um monumento em homenagem a Beethoven, na cidade de Berlin, porém a obra não foi publicamente apresentada. Somente em 1935 ela foi finalizada e entregue a quem a havia encomendado, o dono de uma fábrica de cigarros em Hamburg, Hermann F. Reemtsma.

Por ocasião do nosso primeiro contato com as estatuetas do friso perguntávamo-nos: o que Barlach quis considerar ao associar essas estatuetas à escuta? A que tipo de escuta elas se reportam? Que significados elas segredam/sussurram/murmuram quando queremos compreender o que elas falam? Essas perguntas nos remeteram a outra, isto é, à escuta necessária na vida do professor e às implicâncias da escuta nos processos de ensino-aprendizagem. Assim, este artigo objetiva um mergulho reflexivo nas estatuetas de Barlach no intuito de "ouvir" o que cada imagem tem a nos dizer e a partir dessa "fala" tecer os elos possíveis com as trilhas que percorre o professor ao se entregar à prática pedagógica.

\section{2| PERCURSO METODOLÓGICO}

Tendo feitas as considerações introdutórias, iniciamos agora a segunda parte do trabalho que propõe um exercício de observação ativa tentando ouvir em cada imagem aquilo que ela tem a nos dizer no intuito de responder as perguntas que elas suscitaram em nós'. Sabemos que a incursão e o mergulho nas imagens são permeados por uma forma de escuta particular, singular que diz respeito àquele que escuta. Portanto, as formas de escuta entendidas a partir destas observações e as reflexões subsequentes são relativas à nossa experiência singular de vida, dentro da qual também está cingida a bagagem adquirida no nosso longo percurso como professora.

A seguir, a ordem das figuras olhando o friso de esquerda para a direita:

\footnotetext{
${ }^{1}$ Agradecemos a colaboração da Arte-terapeuta, Linda Fux (Reutlingen, Alemanha) pelas suas contribuições na observação das imagens.
} 
Imagem 1 - Der Fries der Lauschenden. Ernst Barlach (1930-1935)

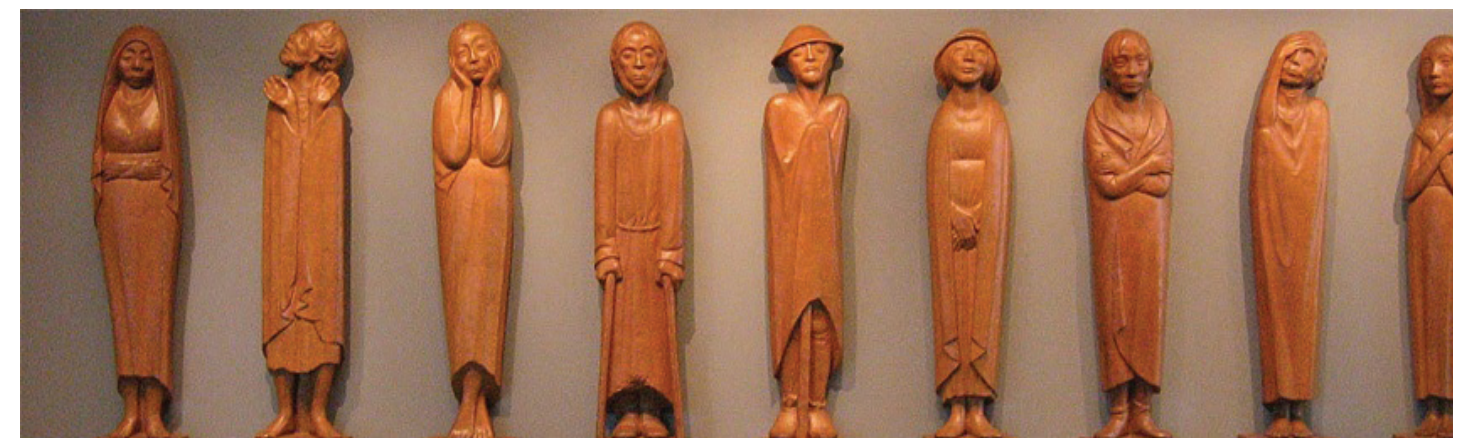

Fonte: Wikipédia (2016).

1. Die Träumende: o sonhador, o visionário.

2. Der Gläubige: o crente, aquele que acredita.

3. Die Tänzerin: a dançarina.

4. Der Blinde: o cego.

5. Der Wanderer: o caminhante.

6. Die Pilgerin: a peregrina, a romeira.

7. Der Empfindsame: o sensitivo, o sensível, o sentimental.

8. Der Begnadet: o perdoado, o inspirado.

9. Die Erwartende: o esperado, o que espera, o bem-vindo.

Die Träumende, o sonhador, é uma figura que insinua a qualidade de quem tem visões e imagens que nem sempre condizem com a realidade palpável, atributo descrito na atmosfera e universo dos contos, sobretudo dos contos de fadas. Segundo o Dicionário de Símbolos ${ }^{2}$, os índios de América do Norte consideram o sonho "o signo final e decisivo da experiência". Dentro de todos os tipos de sonhos, o visionário permite entrar no mundo das imagens e a entrada a esse mundo pressupõe um estado de consciência que segundo H. Corbin (apud CHEVALIER; GHEERBRANT, 2006, p.845) a "civilização ocidental talvez tenha atrofiado ou paralisado". Para C. Jung (apud CHEVALIER; GHEERBRANT, 2006, p. 848), "se sonha em primeiro lugar, e quase exclusivamente, consigo mesmo e através de si mesmo."

Observando a imagem de Barlach, esta estatueta, figura feminina de pés descalços, parece estar quieta, olhando para baixo, mãos cruzadas na altura da cintura, no plexo solar, dividindo o pensar (cabeça) e o sentir (coração) do resto do corpo, isto é da vontade, da ação, do andar. Um manto cobre a cabeça e protege quase a metade do corpo permitindo, talvez, a imaginação criadora e o recolhimento profundo do sonhar ativo. O manto parece estar fechado em cima e embaixo, dando a entender a completude em si mesma da sonhadora. As mãos colocadas no plexo solar e o manto cobrindo só a metade do corpo acentuam o local do plexo, considerado como receptor e emissor de energias. Esta estatueta, ao focalizar o centro de poder, nos sugere a escuta como completude de si, como o recolhimento silencioso do sonhar ativo, como experiência viva, como orientação de vida.

A segunda figura, Der Gläubige, o crente ou aquele que acredita, está ligada a fé e a convicção profunda num mundo que vai além do mundo material, que tece elos com a existência como tal. A estatueta, figura masculina, apresenta o rosto e o olhar dirigidos para cima, a boca aberta, parece estar tendo uma visão. Seus pés descalços transmitem a imagem da "pobreza" no sentido do

${ }^{2}$ Chevalier e Gheerbrant (2006). 


\section{A ESCUTA NA PRÁTICA PEDAGÓGICA | Maria Verónica Pascucci}

desprendimento/despojamento, daquele que está pronto a receber. A posição das mãos parecem a prolongação da orelha ou a postura necessária para aprofundar e aguçar a escuta. Uma segunda interpretação das mãos nos leva a pensar em oferenda, os sacerdotes abrem as mãos para orar, abençoar e para oferecer. As sobrancelhas levantadas indicam atenção, prontidão. Esta figura parece reportar àquele que está à espreita, tentando fazer audível o que não é fácil de ouvir, mostra prontidão, vigilância, consciência, atenção profunda. Além disto, o corpo está coberto e protegido por um manto que só deixa à vista as mãos abertas, em posição de entrega e disposição. O manto cai em linha reta, dentre todos os mantos das estatuetas é o único que cai de forma reta, talvez simbolizando o Eu, a verticalidade da individualidade humana, a consciência. Pés abertos, igual que as mãos, prontos para realizar aquilo que dele se espera. Toda esta figura nos diz: só posso estar à escuta quando eu mesmo conduzo, domino e possuo consciência plena de mim. Remete a uma forma de escuta como atenção plena, e também ao encanto ou encantamento por algo ou alguém.

Para falar da terceira estatueta, die Tänzerin, a dançarina, precisamos nos reportar ao significado da dança. Segundo o Dicionário de Símbolos, a dança é celebração, é linguagem. Linguagem para além da palavra: porque onde as palavras já não bastam, o homem apela para a dança (CHEVALIER; CHEERBRANT, 2006). Através da dança o homem transcende os seus limites e se entrega ao movimento, à expressão, ao fluir. No fresco, os ombros não são paralelos, ela não tem túnica, está aparentemente desprotegida. A dançarina segura o rosto com as duas mãos, como que freando a atividade do pensar. Toda ação parece estar centrada nos pés descalços, ela se segura na ponta dos mesmos já cruzados, dispostos para dançar. Tudo está centrado nos pés descalços, é uma figura graciosa e harmônica que nos insinua um tipo de escuta que transcende o pensar, se sintoniza com o fluir das coisas, da própria vida o que requer um certo estado de abandono, desamparo, estar exposto. "O nosso pensamento aprende com o pé a acertar o passo, e assim construímos uma coluna entre o céu e a terra" afirma Bernhard Wosien, bailarino e pedagogo da dança (WOSIEN, 2000, p. 40). Talvez esse acertar o passo seja encontrar o ritmo de nossa própria vida, o elo que nos une a nós próprios e ao todo no qual estamos inseridos.

Ao dançar, o mundo é de novo circulado e passado de mão em mão. Cada ponto na periferia do círculo é ao mesmo tempo um ponto de retorno. Se dançarmos um dança matinal, saudando o nascer da aurora dançando, perceberemos, quando nos movimentamos ao longo do círculo, como as nossas sombras, neste circular singular, também descrevem um círculo. Assim, nós percebemos que giramos 360 graus. Sentimos na caminhada uma mudança através da reviravolta conjunta. (WOSIEN, 2000, p. 120).

Sem dúvida, aquele que dança está entregue aos sons do universo e no fascínio do movimento redesenha os laços que o unem ao mundo e se abre ao desconhecido pleno de confiança e cheio de uma alegria primordial. Sua forma de escuta é entrega e nudez.

A quarta estatueta representa o cego, der Blinde. Segundo o Dicionário de Símbolos (CHEVALIER; CHEERBRANT, 2006), "o cego" pode apontar para duas situações. Por um lado, indica aquele que não consegue ver a realidade fenomênica, material, simbolicamente falando. Por outro, é aquele que ultrapassa as aparências penetrando na profundidade dos significados. "O cego participa do divino, é o inspirado, o poeta, o taumaturgo, o Vidente". Opera milagres e traz surpresas. A cegueira está associada a provas iniciáticas. Ainda segundo o Dicionário e por causa de uma representação de Homero cego, o cego é símbolo de poeta itinerante. Também significa "aquele que vê outra coisa, com outros olhos, de um outro mundo".

$\mathrm{Na}$ imagem de Barlach, o cego é um homem que permanece de olhos fechados, todo seu corpo apoiado sobre duas bengalas que parecem indicar e acentuar a necessidade de equilíbrio. $O$ cego de Barlach tem uma barba acentuada: segundo o Dicionário de Símbolos, a barba "é símbolo 
de virilidade, de coragem, de sabedoria [...] os heróis, como os deuses, os monarcas e os filósofos são a maior parte do tempo representados com barba" (CHEVALIER; CHEERBRANT, 2006). O cego de Barlach parece calçar botas. Não tem túnica, leva uma corda na cintura. Se a Dançarina, segura a cabeça com as mãos para poder dançar com pés descalços, o Cego, segura os pés calçados para poder pensar. Figura muito simétrica que sugere harmonia e equilíbrio. Esta estatueta nos insinua um tipo de escuta que tendo fechado os olhos, isto é, a percepção do mundo fenomênico se abre em movimento convergente para o in-visível, in-audível de si e do mundo sugerindo abertura para a escuta interior e/ou para a percepção de dimensões outras da vida.

Chegamos à figura do centro, o caminhante, Der Wanderer. O caminhante exposto à intempérie usa chapéu. A expressão da boca, fechada e arqueada para baixo, denota tristeza e abatimento, porém nos fala de uma possível capacidade de mando simbolizada pelo cajado. Segundo o Dicionário de Símbolos, "O bastão aparece na simbólica sob diversos aspectos, mas essencialmente como arma, e sobretudo como arma mágica; como apoio da caminhada do pastor e do peregrino; como eixo do mundo". Outras interpretações e ainda segundo o mencionado dicionário, o designam como símbolo "do tutor, o mestre indispensável na iniciação" (CHEVALIER; CHEERBRANT, 2006). A estatueta do caminhante tem os ombros levantados e os pés bem protegidos, calçando botas. Seu manto aparenta ser um poncho que cobre toda a figura, só deixando à vista o cajado e os pés. Esta estatueta nos faz pressentir uma relação entre aquilo que o caminhante vislumbra como movimento da própria vida e a força com que isso é transformado em ação sugerido pela força de seu cajado ao se fincar na terra.

Ao se referir ao caminhante, o Wanderer, Bollnow (2008, p. 124) afirma:

[...] não se dá valor algum a alcançar determinado rumo no tempo mais curto. Então, nem mesmo os desvios incomodam; pois somente levam mais profundamente para dentro da paisagem [...] não importa a rapidez com que se avança. Não podemos falar sequer de se perder, desde que o Wanderer encontre abrigo para a noite. Somente se perde quem se afasta de um caminho determinado.

Aquele que sabe seu rumo nem se desvia nem se perde, caminha ininterruptamente na mesma direção ou como aponta R. M. Rilke, os caminhos do Wanderer, do caminhante, "centram-se em si mesmos", eles "não se estendem, mas circulam ao redor de seu núcleo", "Wandern (caminhar) é circular ao redor do ponto de equilíbrio da intimidade que se revela por através da paisagem" (RILKE apud BOLLNOW, 2008, p. 127). Se utilizarmos esta metáfora de Rilke para interpretar a estatueta podemos dizer que ela remete a uma escuta de si que implica o estar postado no núcleo, ponto de equilíbrio onde o ser de mim, dos outros e do mundo se revela. Mais acima apontamos o bastão do caminhante como eixo do mundo. Esse núcleo, esse ponto de equilíbrio pode permitir o retorno à "causa de todas as coisas".

[...] há no autêntico Wandern algo como um retorno à ancestral alegria interior, como só pode aparecer na bruma da lembrança, mas então, também, como prenúncio de uma realização futura. A paisagem referida ao próprio centro secreto se revela somente àquele que, no caminhar, retorne a "causa de todas as coisas." (KUNZ apud BOLLNOW, 2008, p. 127).

O caminhar pela vida, em sintonia com o que ela espera de nós, não significa a falta de vicissitudes, angústias, dores e alegrias, mas a serenidade e mansidão surgidas da sintonia e afinação conosco mesmos. Assim como um único instrumento musical desafinado desafina a orquestra toda, assim a não afinação conosco mesmos é fonte de desarmonias e dissonâncias que se fazem sentir das mais variadas formas. 
A próxima figura é feminina, die Pilgerin, a peregrina. Segundo o Dicionário de Símbolos, o peregrino representa o ser humano em busca da terra Prometida, remete a um sentimento de ser estrangeiro e de estar sempre à procura do ideal. Essa atitude refere-se ao desprendimento interior e a ligação com o inalcançável ou inatingível de cada um de nós. Por isso, o peregrino anda na pobreza, é despojado e desprendido, condições que o preparam para a iluminação (Dicionário de Símbolos). No friso de Barlach, a peregrina parece satisfeita não por ter chegado à destino, mas por ter aceito o peregrinar sereno que a nada se prende e que é seu constitutivo.

Ao falar do homem na pós-modernidade Yves de La Taille (2009), utiliza-se das metáforas do turista e do peregrino para esclarecer as características daquele. Essas metáforas referem-se a formas de passar pela vida, ora como turista, ora como peregrino. Assim e em se tratando do peregrino, o autor afirma haver uma "relação entre a viagem e a própria vida" (LA TAILLE, 2009, p. 20). Quando o peregrino volta para casa "ele traz consigo experiências transformadoras e aprendizagens significativas. Leva consigo toda uma memória" (LA TAILLE, 2009, p. 22). Mais adiante e ao se referir a viagem em si o autor continua: "A viagem é, ela mesma, importante, significativa" [...] "O caminho que se percorre é parte integrante da peregrinação" [...] "A viagem é oportunidade de contemplação" (LA TAILLE, 2009, p. 23).

Os conceitos de La Taille comungam com aquilo que a estatueta da peregrina nos sugere, isto é, uma escuta como disposição ao andar (inerente à própria vida). A viagem do peregrino demanda se desfazer das cargas, sejam elas materiais ou emocionais. Quando a única carga é a experiência significativa de si, do outro e do mundo, a liberdade plena é o corolário do próprio andar.

Der Empfindsame, o sensível, o sentimental, o sensitivo, é uma figura masculina, ergue-se refinado e aparenta ter frio. Talvez sinal da solidão do caminhante. Parece calçar botas. Seus pés estão abertos, sinal de prontidão para a recepção de tudo. Em oposição, como gesto contrário, as mãos estão fechadas, postura de estar consigo mesmo.

Se a condição para a percepção é estar aberto, ela pressupõe estar consigo, fechado em si mesmo. Dessa maneira, na imagem de Barlach, o peito está aberto, de prontidão à recepção e as mãos fechadas impedindo a ação, simbolizada aqui pela posição do cotovelo que fechado estabelece um espaço, um corte, um hiato entre a percepção e a ação.

Ao se referir aos sentidos da sensibilidade, Lima de Araújo (2009, p. 202) escreve:

A dis-posição do estado sensível nos possibilita o estar-sendo-no-mundo-com-os-outros, de modo encarnado e radical, mediante os processos de percepção e de compreensão em que podemos tocar, cheirar, escutar, saborear e olhar o mundo, bem como, conjuntamente, pensar, meditar por meio de nossa relação direta e originária com ele. Essa disposição desemboca em formas de saber - sapere - imbuídas do elã do vivido-vivente que traduzem um "enraizamento dinâmico."

Entendemos essa disposição à qual Araújo se refere como um estado de abertura e atenção plena que nos faz estar inteiramente enraizados naquilo que fazemos e profundamente ligados àqueles com os quais nos comunicamos, assim fazemos experiência, assim nasce o saber da experiência. Esta estatueta nos fala de uma escuta que abrange percepção e sensação, aponta para aquele que ao se perceber/sentir a si mesmo percebe e sente o outro, o mundo, sendo essa percepção fonte de experiência e fonte de saber.

A oitava estatueta representa Der Begnadet. Para traduzir esta palavra precisamos nos reportar tanto ao Alemão quanto ao Inglês, posto que não temos uma tradução literal para o Português que se aproxime ao sentido da imagem. Assim, Der Begnadet refere-se ao perdoado, ao inspirado, ao altamente dotado, talentoso, ao abençoado. Todas estas interpretações parecem estar presentes no manto que com três dobras cobre o corpo brindando proteção total e preparando-o 
para receber algo. O olhar desta figura masculina aponta para o oeste, parece dirigido a um mundo que ofusca e deslumbra e suscita tanto admiração quanto ilusões e desejos, nem sempre fatíveis de ser realizados, por isso ele precisa proteger o olhar. Aqui aparece mais uma figura de pés descalços que, como apontamos na interpretação da segunda estatueta, sugere-nos o desprendimento e despojamento daquele que está pronto a receber. Esta escuta parece remeter a certa aceitação do próprio destino e à abertura necessária para tal disposição.

Ao se referir ao mundo técnico e a nossa relação com ele, Heidegger (2007, p. 8, tradução nossa) afirma:

O sentido do mundo técnico se oculta. Pois bem, se atendermos da mesma forma con-
tinuada, ao fato de que por todas partes nos alcança um sentido oculto do mundo técnico
imediatamente entraremos no âmbito do que se nos oculta e que se oculta na medida em
que vem ao nosso encontro. O que desta forma se mostra e ao mesmo tempo se retira é
o rasgo fundamental do que chamamos mistério. Denomino a atitude pela qual nos man-
temos abertos ao sentido oculto do mundo técnico a abertura ao mistério (grifo nosso).

O técnico ao qual Heidegger se refere está relacionado ao modo como percebemos e apreendemos o mundo. No seu discurso, Gelassenheit, o filósofo aponta para a perda da reflexão meditativa em nome do pensar calculador que se instaurou na humanidade atual e que modifica radicalmente a relação do homem com a natureza, com o mundo, com os outros. Esse pensar reflexivo permite a abertura ao mistério do mundo. A estatueta em questão aponta para um escuta receptiva, dinâmica na sua abertura, serena na sua própria solicitude, entregue ao seu próprio destino.

Chegamos à nona e última imagem, Die Erwartende, o esperado e o que espera, o bem-vindo. Figura que não é apresentada de frente, mas virada para o oeste. As igrejas e catedrais do Cristianismo são construídas olhando para o poente no intuito dos fiéis ao estar defronte ao altar olharem para o oriente, lugar "do nascimento do sol". O sagrado aponta para o sol e os astros celestes. A palavra oriente deriva de outras duas, do Latim, Oriens ${ }^{3}$ que remete ao lugar do nascimento do sol e Oriri que significa, nascer, crescer, levantar-se. Da palavra oriente também derivam orientar e orientação, não tão somente referido a uma questão geográfica, mas a encontros significativos que podem indicar um rumo, ao encontro de caminhos de vida. No caso do Erwartende, este parece ser comparado, pela sua posição, ao sacerdote que virado para o oriente consagra o pão e o vinho que entregará depois aos fiéis. Podemos dizer, então, que o Erwartende, na condição daquele que espera ou daquele que é esperado, reconhece as situações, está expectante, pronto a receber, aguarda para agir depois. É receptivo, acolhe e cuida. O termo Erwarten está ligado à palavra Empfangen, que denota receptividade, acolhimento, sensível e predisposto e, referido à mulher, significa aquela que concebe. No fresco de Barlach, o Erwartende parece ser uma figura feminina, cujos braços cruzados imitam a postura de Maria quando o Anjo lhe anuncia a gravidez. Esta estatueta, ao igual que a anterior, sugere um tipo de escuta receptiva, aberta ao mistério, à presença intima originária que faz parte da condição humana.

${ }^{3}$ Origem... ([201-]). 


\section{6 | CONCLUSÃO}

Se destacarmos alguns termos e ideias "sussurradas" a nós pelas estatuetas, tais como completude de si, recolhimento silencioso do sonhar ativo, orientação de vida, prontidão, atenção profunda, consciência plena, encantamento, movimento convergente para o in-visível e in-audível, abertura para a escuta interior, apelo de si, disposição para o andar, experiência significativa de si, do outro e do mundo, liberdade plena, escuta como percepção e sensação, fonte de saber, aberta ao mistério, à presença intima originária que faz parte da condição humana, podemos afirmar que todas elas são desdobramentos de uma única forma de escuta, a escuta de si, à qual chegam todos aqueles dispostos a entregar-se a ela.

À escuta de si pertence uma voz ou o silêncio dessa voz. Como seres pensantes estamos abertos ao nosso ser que ora fala, ora silencia. O ser, por sua vez, só pode ser enquanto ouvido por nós. Para Heidegger o ser apela e se deixa ouvir quando estamos "afinados" com ele, postados na clareira do mesmo. A clareira do ser é a sua revelação. O ser de nós, do mundo e das coisas se revela a nós quando postados à clareira do mesmo dispostos a ouvir seu apelo.

Nas suas palavras,

Ser somente é e permanece enquanto aborda o homem pelo apelo. Pois somente o homem, aberto para o ser, propicia-Ihe o advento enquanto presentear. Tal presentear necessita o aberto de uma clareira e permanece assim, por esta necessidade, entregue ao ser humano, como propriedade. Isto não significa absolutamente que o ser é primeira e unicamente posto pelo homem. Pelo contrário, torna-se claro. (HEIDEGGER, 2009, p. 44).

Assim, a escuta de si permite ouvir a voz que orienta a vida e requer o recolhimento profundo do sonhar ativo transformado em experiência viva, como orientação de vida. A experiência viva é lavareda transformada em sabedoria. Essa sabedoria, que nos pertence como corolário da nossa caminhada, transcende o pensar e se sintoniza com o fluir da própria vida, exigindo apenas entrega, confiança, nudez. Como afirma Kovadloff (2003, p. 79), "Ouvir, mais do que estar disposto, é estar exposto."

Se a escuta de si é estar postado à clareira do ser que apela para ser ouvido (Heidegger), essa voz que fala desde a sua identidade precisa da nossa oferenda e somente assim se revela como palavra-guia da vida. Acreditamos que o segredo da liberdade é a obediência ao ideal-guia que marca o rumo da vida. Esse ideal nem sempre está pronto ou claro, ele vai se re-velando e des-velando no acontecer da própria caminhada.

Lyotard (1997, p. 169), ao se referir à escuta nos tempos da tecnologia aponta para:

[...] uma destinação da escuta para a escuta, uma "obediência" que deveríamos talvez qualificar de absoluta, um ouvido dado ao outro ouvido: uma destinação que excede, em todo o caso, o alcance das pesquisas tecnocientíficas imaginadas do ponto de vista técnico, graças às quais esta obediência é, no entanto, revelada.

Concluindo, a escuta pode acercar-nos aos domínios do ser, o outro de nós, porta ao sagrado e ao mundo dos deuses. O homem à escuta de seu ser-sagrado, abre-se ao mistério, entrega-se à transcendência e dignifica a vida, dando-Ihe um sentido outro, profundo, singular, ímpar, original. Nos tempos de fuga que vivemos, de urgências e apelos vindos de fora "Nenhuma saída pode ser tão nobre quanto a permanência em si mesmo", como aponta Mestre Eckhart (2004). Na escuta de si reside a completude do existir que nos mantém unidos a nós, aos outros, ao mundo.

Levando tais considerações ao campo da prática pedagógica e especialmente à escuta neces- 


\section{A ESCUTA NA PRÁTICA PEDAGÓGICA | Maria Verónica Pascucci}

sária à vida do professor, podemos afirmar que não há escuta do outro se não houver escuta de si. Essa escuta de si pode ou não ser construída ao longo da vida, pertence ao âmbito da decisão individual e singular de assumir a autoria da própria vida. Dentro desse "livro" escrito por todos e cada um de nós, o tema da escuta é essencial, sobretudo na vida do professor, pois a prática pedagógica requer uma escuta apurada, sensível e plena sem a qual não podemos escutar o que o aluno tem a dizer ou precisa dizer. Talvez nós professores sejamos, ora um, ora outro, todos e cada um dos personagens esculpidos por Barlach que na sua caminhada se abrem à escuta plena do mundo.

Neste sentido, vêm ao nosso encontro às palavras de Ostetto, que ao se referir ao processo educativo como encantar-se para encantar sugere o abrir-se, "[...] à escuta e ao olhar do inusitado e misterioso, acolhendo múltiplos sentidos no mundo, para poder ser sensível e acolher diferentes significados e sentidos construídos pelas crianças no cotidiano educativo; ousar para poder encorajar" (OSTETTO, 2010, p. 45).

No contexto deste trabalho nós sugerimos o escutar-se para escutar, pois a escuta é o báculo que ampara e acompanha o trilhar dos caminhos de incerteza que se estendem a nossa frente, ininterruptamente. Escuta é cuidado e, na prática pedagógica cuidado é um ato de amor. 


\section{REFERÊNCIAS}

ARAÚJO, M. A. L. de. Os sentidos da sensibilidade e sua fruição no fenômeno do educar. Educação em Revista, Belo Horizonte, v. 25, p. 1999-222, 2009.

BOLLNOW, O. F. O homem e o espaço. Tradução Aloísio Leoni Schmid. Curitiba: Editora UFPR, 2008.

CHEVALIER, J.; CHEERBRANT, A. Dicionário de símbolos. 20. ed. Rio de Janeiro: José Olympio, 2006.

ECKHART, Mestre. Sobre o desprendimento e outros textos. São Paulo: Martins Fontes, 2004.

HEIDEGGER, Martin. Que é isto - A Filosofia? Identidade e Diferença. Trad. de Ernildo Stein. $2^{a}$ Edição. Petrópolis, RJ: Vozes, São Paulo, Livraria Duas Cidades, 2009.

Ser e verdade: a questão fundamental da filosofia: da essência da verdade. Trad. Emanuel Carneiro Leão. Petrópolis, Vozes, Bragança Paulista: Editora Universitária São Francisco, 2007. Coleção Pensamento Humano.

KOVADLOFF, S. O silêncio primordial. Rio de Janeiro: José Olympio Editora, 2003.
LA TAILLE, Y. de. Formação ética: do tédio ao respeito de si. Porto Alegre: Artmed, 2009.

LYOTARD, J.-F. O Inumano: considerações sobre o tempo. Lisboa: Editorial Estampa, 1997.

ORIGEM da palavra: site de etimologia. [201-]. Disponível em: <http://origemdapalavra.com.br/site/?s=oriens>. Acesso em: 10 fev. 2016.

OSTETTO, L. E. Para encantar, é preciso encantar-se: danças circulares na formação de professores. Cadernos Cedes, Campinas, v. 30, n. 80, p. 40-55, jan./abr. 2010. Disponível em: <http://www.cedes.unicamp.br>. Acesso em: 08 fev. 2016.

PASCUCCI, Maria Verónica. Silêncio, arte e educação transformadora. EDUFMA: São Luís, 2011.

WIKIPÉDIA. Ernst Barlach. 2016. Disponível em: <https://de.wikipedia.org/wiki/Ernst_Barlach>. Acesso em: 10 dez. 2012.

WOSIEN, B. Dança: um caminho para a totalidade. São Paulo: Triom, 2000. Disponível em: <http://www.dancascirculares.org/>. Acesso em: 10 fev. 2016. 